\title{
On the role of US expectancies in avoidance behavior
}

\author{
Mieke DeclercQ And Jan De Houwer \\ Ghent University, Ghent, Belgium
}

\begin{abstract}
In studies on avoidance learning, a warning signal is followed by an aversive outcome (US) unless the participant makes a particular response. Several theories have been developed to try to explain the mechanisms underlying avoidance learning. Surprisingly, stimulus-response (S-R) theories and cognitive theories of avoidance learning have rarely been compared experimentally. These theories differ in the role they assign to the US representation in avoidance learning. We used a method often used to investigate the contribution of the US representation - namely, US revaluation. Participants first learned to avoid two different negative USs. In a revaluation phase, the value of one US became positive, whereas the value of the other US remained the same. The results indicated that after the revaluation phase, participants avoided the positive US less than the negative US. These results cannot be explained by S-R theories of avoidance learning.
\end{abstract}

People often behave in a certain manner in order to prevent something bad from happening. For instance, putting on a raincoat prevents you from getting wet, or stopping before a red traffic light prevents a collision with another car. These are examples of avoidance behavior, in which an instrumental response avoids the occurrence of an aversive event.

In most studies on avoidance behavior, a warning signal (A) is followed by an aversive unconditioned stimulus (US), unless a particular behavior (R) is emitted. For example, a dog can receive an electric shock (US) after a light (A) is turned on, unless the dog jumps across a hurdle (R) into another chamber of the shuttle box (see, e.g., Solomon \& Wynne, 1953). Research on this topic was at the center of learning psychology for decades, but since the 1970 s, interest in this type of learning has dwindled. This is remarkable, because many theoretical issues remain unresolved.

One of the unresolved issues relates to the importance of the US representation in avoidance behavior. This debate is not limited to avoidance learning. For example, in the field of classical conditioning, many experiments were conducted to test whether US representations are crucial. Most of these experiments provided evidence for the involvement of US representations in classical conditioning (e.g., Rescorla \& Cunningham, 1978; Vansteenwegen, Crombez, Baeyens, Hermans, \& Eelen, 2000). Despite the large amount of research on this topic in classical conditioning, the role of US representations in avoidance learning has rarely been investigated experimentally. According to stimulus-response (S-R) theories of avoidance learning, learning about the relation between the warning signal and the avoidance response is crucial. Once this relation has been learned, the avoidance response is elicited auto- matically after the presentation of the warning signal. A typical S-R theory is the original version of the two-factor theory (Mowrer, 1947), which has both a Pavlovian and an instrumental component. First, Pavlovian conditioning of fear to the warning signal is required: Pairing the warning signal with the US results in a conditioned response of fear to the warning signal. Second, an instrumental learning process is involved, in which one learns to perform a particular behavior. Initially, an escape response is performed: The behavior is emitted during the presence of the US and is reinforced by the termination of the US. When it becomes an avoidance response that is emitted before the US is presented, it is reinforced by the reduction in fear as a consequence of the termination of the warning signal. In the original formulation of the two-factor theory, avoidance learning is thus explained without assigning any role to a mental representation of the US. The avoidance behavior is not emitted to prevent a US from being presented in the future, but is elicited automatically by the warning signal as the result of reinforcement by the termination of the US and the warning signal.

However, more cognitive theories were also developed, in which the US representation is crucial in the maintenance of an avoidance response. An avoidance response is then performed to avoid the occurrence of the US. One example of a cognitive theory is the theory of Seligman and Johnston (1973; see De Houwer, Crombez, \& Baeyens, 2005, and Lovibond, 2006, for more recent cognitive theories). Seligman and Johnston postulated that an individual expects a US when no response is made in a given interval after the presentation of a warning signal and expects no US when a response is made within that interval. A second principle poses that individuals not only acquire expectancies but also have certain preferences-namely,

M. Declercq, miekee.declercq@ugent.be 
that the absence of a US is preferred to the presence of a US. Because of these preferences, human and nonhuman animals will use their knowledge of the relation between the avoidance behavior and the US to try to prevent the occurrence of the US.

We know of only one study that directly compared S-R theories with cognitive theories. In this study, by Hendersen and Graham (1979), rats first learned to avoid heat in a room with an ambient temperature of $27^{\circ} \mathrm{C}$ : The rats learned to jump on a ledge after a warning signal was presented in order to avoid the presentation of heat that was administrated through heat lamps. After this training phase, the rats were placed in a cold $\left(7^{\circ} \mathrm{C}\right)$ room for $2 \mathrm{~h}$. During this period in the cold room, half of the rats were exposed to heat from the same heat lamps, and the other half received no heat. This was done to give half of the rats a direct experience with the positive properties of heat in a cold room. Four days later, series of extinction trials for the avoidance response were presented to the rats when they were sitting in either a $7^{\circ} \mathrm{C}$ room or a $27^{\circ} \mathrm{C}$ room. On these extinction trials, only the warning signal was presented; rats received no heat. The results indicated that cold ambient temperature facilitated extinction of the avoidance response. If the rats were sitting in the cold room, they performed fewer avoidance responses than did the rats sitting in the warm room. However, these results were found only with rats that had previously experienced the positive properties of the heat lamp in the cold. The results can be explained on the basis of cognitive models of avoidance learning: All rats (initially) expected the heat during the extinction trials, but those that had directly experienced that heat is positive in a cold room no longer had reason to avoid the heat when they were in a cold room.

Although their results are in line with cognitive theories of avoidance learning, Hendersen and Graham (1979) themselves point out that the results can also be explained on the basis of S-R theories. Rats that experienced the (positive) heat in a cold room might have become less frightened of the heat lamps when they were presented in a cold room. If so, these rats would have experienced less fear during the extinction trials that took place in a cold room, which would result in less reinforcement of avoidance responses by fear reduction. According to this account, the difference between groups is due to differences in reinforcement during the extinction phase. In line with this idea, Hendersen and Graham found no differences between groups on the first extinction trial, in which no additional learning could have occurred, but only on subsequent extinction trials. Although this aspect of the data seems to favor S-R theories, one could also explain it on the basis of cognitive theories if one assumes that the rats needed some time to integrate the knowledge they acquired during the various phases of the experiments.

The evidence regarding the important question of whether S-R or cognitive theories underlie avoidance behavior is thus limited in several respects: There has only been one set of studies (Hendersen \& Graham, 1979), with one nonhuman species, which produced inconclusive results. We therefore conducted a new experiment, in which we tested whether S-R or cognitive theories can
Table 1

Summary of the Design

\begin{tabular}{cclcc}
\hline Phase 1 & Phase 2 & \multicolumn{1}{c}{ Phase 3 } & Revaluation & Test \\
\hline US1: neg & A-US1 & A-R1-US1 absent* & US1: pos & A-R1 \\
US2: neg & B-US2 & B-R2-US2 absent* & US2: neg & B-R2 \\
& & & \\
& & A-US1 & \\
& & & \\
\end{tabular}

*The US1 or the US2 was absent only if participants pressed the appropriate key.

explain avoidance learning in humans. We used a method that was often used in research on the role of US representations in classical conditioning - namely, US revaluation (Rescorla, 1980). The design is given in Table 1. In a first phase, participants were familiarized with two different USs (i.e., a red letter "X" and a red letter "Y," both signaling the loss of money). In a second phase, Warning Signal A was always followed by US1 and Warning Signal B was always followed by US2. In a third phase, participants again received the two warning signals but now had the opportunity to press Key R1 after Warning Signal A and Key R2 after Warning Signal B. Key R2 was not available after Warning Signal A and Key R1 was not available after Warning Signal B. Warning Signal A was followed by the US1 unless Key R1 was pressed and Warning Signal B was followed by the US2 unless Key R2 was pressed. After this phase, the two USs were presented in the absence of the warning signals and the value of US1 became positive (i.e., US1 indicated the gain of money; US revaluation), whereas the value of the US2 stayed identical. We then investigated whether US revaluation influenced the probability that the avoidance responses would be emitted after presentation of the warning signals. More specifically, on the basis of cognitive theories, we expected that after US revaluation, the avoidance behavior associated with US1 would be emitted less frequently than the avoidance behavior associated with US2.

As Hendersen and Graham (1979) pointed out, in order to rule out an S-R account, it is important that the effect of the revaluation is already present on the first test trial. This is because additional $\mathrm{S}-\mathrm{R}$ learning can take place during test trials. We therefore focused on the first test trial after the revaluation phase.

\section{METHOD}

\section{Participants}

Twenty-four students at Ghent University were paid in exchange for their participation. The exact amount (on average, $€ 4$ ) depended on how successful they were in avoiding USs.

\section{Stimuli and Materials}

The experiment was run on a portable computer with a 15-in. screen and was controlled by an Inquisit 2.0 program (Millisecond Software, Seattle). The warning signals were a white triangle and a white square, each $2 \times 2 \mathrm{~cm}$. The assignment of a shape (square or triangle) to a stimulus (A or B) was counterbalanced. Two different USs were used: For half of the participants, US1 was a $2 \times 2 \mathrm{~cm}$ red "X" and US2 a $2 \times 2 \mathrm{~cm}$ red "Y." For the other half of the participants, this was reversed. The stimuli were presented in a main frame that measured $20 \times 13 \mathrm{~cm}$ and appeared at the center of the screen. At the top of this main frame, a second frame was visible, which was 
$9 \times 1.5 \mathrm{~cm}$. In this frame, a message could appear about whether a certain key was available on a particular trial. At the bottom, a third frame of $5 \times 1.5 \mathrm{~cm}$ was drawn. In this frame, a small blue or green bar of $2 \times 0.5 \mathrm{~cm}$ was presented after a correct response by the participant was registered. The avoidance responses were presses on the "D" or "K" keys of an AZERTY keyboard that was connected to the computer. On the " $D$ " key, a green label was attached, whereas a blue label was attached to the "K" key. All instructions and messages appeared in Dutch.

\section{Procedure}

Participants took part individually in a dimly lit room. After signing an informed consent form, they were seated at a distance of approximately $60 \mathrm{~cm}$ from the screen and were given written instructions in Dutch. Participants were told that they had received a credit of $€ 8$. The presentation of the red "X" and "Y" could be coupled with a loss of $€ 0.25$ or a gain of $€ 0.25$. The main task of the participants was to avoid losing money, and they were told that they could take home the amount of money that remained at the end of the experiment. They would be able to avoid the red "X" and "Y" by using certain keys when they were available. The availability of the keys would be signaled by a message. After the participants indicated that they had read the instructions, the experimenter demonstrated how the responses should be executed. On these demonstrations, no stimuli were presented. The only available key for these demonstration trials was the space bar.

During a first learning phase, participants received four trials in which US1 was presented and four trials in which US2 was presented. The aim was to familiarize participants with the USs. As in all other phases, the trials were presented in a random order. On all trials of the first phase, the US was presented $1,500 \mathrm{msec}$ after the onset of the frame and remained on the screen for $1,500 \mathrm{msec}$. A message, which informed participants that their credit had diminished by $€ 0.25$, was presented above the US, $500 \mathrm{msec}$ after the onset of each US. This message remained on the screen for $1,000 \mathrm{msec}$. The intertrial interval was $5,000 \mathrm{msec}$.

In a second learning phase, participants saw four trials in which Warning Signal A and the US1 were presented (A-US1 trials) and four trials in which Warning Signal B and the US2 were presented (B-US2 trials). On all trials, the warning signal appeared in the center of the screen $1,500 \mathrm{msec}$ after the onset of the frame and remained on the screen for $2,000 \mathrm{msec}$. One of the two USs was presented in the center of the screen $6,000 \mathrm{msec}$ after the warning signal had disappeared and remained on the screen for $1,500 \mathrm{msec}$. Above the US, a message appeared $500 \mathrm{msec}$ after the onset of the US, showing the participants that their credit had diminished. The message remained on the screen for $1,000 \mathrm{msec}$, after which the entire screen was cleared. The intertrial interval was $5,000 \mathrm{msec}$. All trials were presented in a random order that differed for each participant. It should be noted that in this phase, neither of the avoidance response keys was available. If the participants did, however, press a key, this had no influence on the presentation of the USs.

The third phase started immediately after the first one. In this phase, two A-US1 trials and two B-US2 trials were presented. Additionally, four trials were presented in which Warning Signal A was presented and Key R1 was available (AR1 trials) and four trials in which Warning Signal B appeared and Key R2 was available (BR2 trials). Whether the green or blue key functioned as Key R1 or Key R2 was counterbalanced. The AR1 and BR2 trials were identical to the A-US1 and B-US2 trials except on the following points. First, after the shape disappeared, the message "Blue key is available" or "Green key is available" appeared on the screen and remained there for $5,000 \mathrm{msec}$. If the available key was pressed during these 5,000 msec, a registration bar in the corresponding color of the key appeared on the screen for $1,000 \mathrm{msec}$ as soon as the message in which the availability of a key was signaled had disappeared and no US was presented. In that case, $1,500 \mathrm{msec}$ after the presentation of the registration bar, a message appeared at the center of the screen, which informed participants that their credit remained unchanged. If the available key was not pressed, or was pressed before or after the message was displayed on the screen, the registration bar was not presented and the trial ended as a US-present trial.

After this third learning phase, a revaluation phase was presented that was identical to the first learning phase except on the following point: If US1 was presented, a message appeared above the US in which participants were told that their credit had increased by $€ 0.25$.

A test phase followed immediately after the revaluation phase. In this phase, four AR1 and four BR2 trials were presented. These trials were identical to the AR1 and BR2 trials in the second phase except for the message that appeared when participants did not press the available key that avoided the revalued US (US1). In this case, a message appeared in the upper right corner telling the participants that their credit had increased by $€ 0.25$.

\section{RESULTS}

To clearly distinguish between a cognitive and an S-R point of view, it is important to investigate whether, on the first trial after revaluation, R1 is emitted less frequently than R2. We tested this by comparing two proportions. The first proportion was the proportion of participants who performed Avoidance Response R1 on the first trial, in which this response was possible after the revaluation phase (6 out of 24). The second was the proportion of participants who performed Avoidance Response R2 on the first trial, in which this response was possible after the revaluation phase (22 out of 24). The McNemar (1947) test, a test that compares two related proportions, indicated a significant difference $(p<.001)$.

Next, we calculated for each participant the number of avoidance responses on the four AR1 and four BR2 trials of the third phase and the test phase. An ANOVA with within-subjects factors phase (third phase vs. test phase) and response (R1 vs. R2) indicated a main effect of phase $[F(1,23)=114.50, p<.001]$, a main effect of response $[F(1,23)=76.47, p<.001]$, and a significant interaction $[F(1,23)=90.39, p<.001]$. Planned comparisons showed that R1 was emitted more frequently before $(M=$ $3.79, S D=0.41)$ than after $(M=0.62, S D=1.10)$ the revaluation phase $[F(1,23)=140.73, p<.001]$. No significant difference was found in the use of R2 before $(M=$ $3.50, S D=0.66)$ and after $(M=3.58, S D=0.58)$ the revaluation phase $[F(1,23)<1]$. Before the revaluation phase, the number of R1 responses $(M=3.79, S D=0.41)$ was somewhat larger than the number of $\mathrm{R} 2$ responses $(M=3.50, S D=0.66)[F(1,23)=5.24, p<.05]$. After the revaluation phase, however, R1 responses $(M=0.62$, $S D=1.10)$ were less frequent than $\mathrm{R} 2$ responses $(M=$ $3.58, S D=0.58)[F(1,23)=98.67, p<.001]$.

\section{DISCUSSION}

We compared cognitive and S-R theories of avoidance learning by examining the effect of US revaluation on the frequency with which an avoidance behavior is performed. According to $\mathrm{S}-\mathrm{R}$ theories, a change in the reinforcing properties of the US should have no effect on the performance of avoidance behavior, whereas cognitive theories predict that a difference in performance will occur. The results showed that, after revaluation, the response associated with the revaluated US (R1) was emitted less fre- 
quently than the response associated with the nonrevaluated US (R2). Before revaluation, this was not the case. (For some unclear reason, R1 was even emitted a bit more frequently than R2.) Importantly, the difference after revaluation was present from the first test trial onward. This demonstrates that the performance of avoidance behavior is mediated by the US representation, a finding in line with cognitive theories of avoidance behavior but incompatible with $\mathrm{S}-\mathrm{R}$ theories of avoidance behavior.

Similar results were reported by Hendersen and Graham (1979), who found that manipulating the reinforcing properties of the US had an influence on the speed of extinction of avoidance behavior. However, our experiment is different from that of Hendersen and Graham in at least two ways. First, whereas they studied avoidance behavior in rats, we are the first to study the effects of US revaluation on avoidance learning in humans. Second, Hendersen and Graham did not demonstrate that US revaluation had an immediate effect on avoidance behavior. This is problematic, because it leaves open a possible explanation of their findings in terms of S-R models. In our experiment, we found that R1 was emitted less frequently than R2 even on the first trial after revaluation in which these responses were possible. We can therefore exclude the possibility that differences in reinforcement after the revaluation were responsible for the effects of US revaluation.

In the reported experiment, we used a nonverbal revaluation procedure in which participants experienced the change in the value of the US. We also conducted two replications of the present experiment, in which the revaluation phase was replaced by instructions (i.e., a written message stating that, from that moment on, US1 would lead to a gain of $€ 0.25)$. The replications produced the same effects as the study described in this article, including the effects on the first test trial. This not only attests to the reliability of our results, it also suggests that the nature of the US revaluation procedure (verbal or nonverbal) does not have a major influence on the effectiveness of US revaluation. The latter conclusion is in line with recent findings in the literature on human associative learning, which strongly suggest that human learning is often, if not always, based on conscious, propositional reasoning processes rather than on the automatic formation of associations in memory (De Houwer, Vandorpe, \& Beckers, 2005; Lovibond, 2003, 2006).

Although the results give strong evidence for cognitive theories of avoidance behavior, some limitations should be mentioned. One limitation concerns the use of money loss as an aversive US. A small loss of money can perhaps not be regarded as a truly aversive US. Despite the fact that De Houwer, Crombez, and Baeyens (2005) found no difference in their results when they used a neutral US (i.e., a letter that participants were instructed to avoid) as opposed to a mildly aversive US (i.e., a mild electrocutaneous stimulus), it would be interesting to repeat our experiment with more aversive USs, to test the generalizability of our results. Another limitation is that we did not explore the impact of the number of acquisition trials. Studies on US revaluation in classical conditioning have shown that
US revaluation becomes less effective when the CS-US relation is trained beyond asymptote. It is therefore possible that US revaluation will not affect avoidance behavior when more trials are presented in which the warning signal is paired with the negative US. Thus, although there are issues that need to be resolved in future research, the present article does offer a first, important step in providing evidence for cognitive theories of avoidance behavior.

Finally, our results also have clinical implications. Avoidance behavior lies at the core of many forms of psychopathology. The results of our study show that avoidance behavior can be mediated by the representation of the US. This suggests that, in clinical practice, changing the perceived value of the expected outcomes can change an avoidance behavior as it can change a conditioned fear response.

\section{AUTHOR NOTE}

This research was funded by Grant BOF-01100805 from Ghent University. Correspondence concerning this article should be addressed to M. Declercq, Department of Experimental Clinical and Health Psychology, Ghent University, Henri Dunantlaan 2, B-9000 Ghent, Belgium (e-mail: miekee.declercq@ugent.be).

\section{REFERENCES}

De Houwer, J., Crombez, G., \& Baeyens, F. (2005). Avoidance behavior can function as a negative occasion setter. Journal of Experimental Psychology: Animal Behavior Processes, 31, 101-106.

De Houwer, J., VANDORPe, S., \& Beckers, T. (2005). On the role of controlled reasoning processes in human associative learning. In A. Wills (Ed.), New directions in human associative learning (pp. 41-63). Mahwah, NJ: Erlbaum.

Hendersen, R. W., \& Graham, J. (1979). Avoidance of heat by rats: Effect of thermal context on rapidity of extinction. Learning \& Motivation, 10, 351-363.

Lovibond, P. F. (2003). Causal beliefs and conditioned responses: Retrospective revaluation induced by experience and by instruction. Journal of Experimental Psychology: Learning, Memory, \& Cognition, 29, 97-106.

LoviBond, P. F. (2006). Fear and avoidance: An integrated expectancy model. In M. G. Craske, D. Hermans, \& D. Vansteenwegen (Eds.), Fear and learning: Basic science to clinical application (pp. 117132). Washington, DC: American Psychological Association.

McNemar, Q. (1947). Note on the sampling error of the differences between correlated proportions of percentages. Psychometrika, 12, 153-157.

Mowrer, O. H. (1947). On the dual nature of learning: A reinterpretation of "conditioning" and "problemsolving." Harvard Educational Review, 17, 102-148.

Rescorla, R. A. (1980). Pavlovian second-order conditioning. Hillsdale, NJ: Erlbaum.

Rescorla, R. A., \& Cunningham, C. L. (1978). Within-compound flavour associations. Journal of Experimental Psychology: Animal Behavior Processes, 4, 267-275.

Seligman, M. E. P., \& Johnston, J. C. (1973). A cognitive theory of avoidance learning. In F. J. McGuigan \& D. B. Lumsden (Eds.), Contemporary approaches to conditioning and learning (pp. 69-110). Washington, DC: Winston-Wiley.

Solomon, R. L., \& Wynne, L. C. (1953). Traumatic avoidance learning: Acquisition in normal dogs. Psychological Monographs, 67, 1-19.

Vansteenwegen, D., Crombez, G., Baeyens, F., Hermans, D., \& EELEN, P. (2000). Pre-extinction of sensory preconditioned electrodermal activity. Quarterly Journal of Experimental Psychology, 53B, 359-371.

(Manuscript received November 15, 2006; revision accepted for publication June 23, 2007.) 